\title{
Joining forces: Collaborating internationally to deliver high-quality, online postgraduate education in pain management
}

\author{
Elizabeth Devonshire RN MHSc(Ed) EdD, Philip J Siddall MBBS MM(Pain Mgt) PhD FFPMANZCA
}

\begin{abstract}
E Devonshire, PJ Siddall. Joining forces: Collaborating internationally to deliver high-quality, online postgraduate education in pain management. Pain Res Manage 2011;16(6):411-415.
\end{abstract}

The effective management of pain is a complex and costly global issue, requiring a range of innovative educational strategies to enable culturally appropriate and high-quality health care provision. In response to this issue, the Pain Management Research Institute at the University of Sydney (Sydney, Australia) has established several strategic alliances with other overseas universities to deliver online postgraduate education in pain management. The present article discusses the rationale for joining forces, and the approach adopted in creating and maintaining these alliances. It also provides insights into the benefits, challenges and opportunities associated with collaborative educational initiatives of this nature, from institutional, academic and student perspectives.

Key Words: Educational collaboration; Internationalization; Online education; Pain management; Partnership; Postgraduate

\section{THE PROBLEM OF PAIN}

The effective management of pain is an increasing concern in the medical arena, and in the broader economic and political environment. One issue is that the management of pain conditions is a costly business, not just in financial terms but also in relation to the associated social and workplace costs. In Australia, for instance, the management of pain accounts for the third highest cost in the health care system, following cardiovascular disease and musculoskeletal conditions; it is estimated that chronic pain costs more than AUS\$34 billion annually (1). Other regions, such as North America and the European Union, provide similar accounts of the economic burden of chronic pain, in both direct and indirect terms (2,3). Another issue is that many pain problems are diverse and complex in nature, necessitating a multidisciplinary team approach to pain treatment and management (4).

One strategy to help address this situation is the provision of highquality education opportunities that develop the capabilities of health professionals to effectively manage the problem of pain. Such education opportunities must be integrated across both formal programs of professional training and informal continuing education agendas. They also need to harness recent advances in information and communication technologies, and prepare graduates for global citizenship, ie, graduates who aspire to contribute to society in a full and meaningful way through their roles not only as members of local and national communities, but also the wider global community.

With these issues in mind, the present article describes a case study of the internationalization of a Master's program via the development of strategic alliances between the Pain Management Research Institute at the University of Sydney (Sydney, Australia) and three overseas universities. The aim of these alliances was to facilitate the delivery of an international online pain education program at a graduate level of study to health professionals across the globe. The term 'strategic alliance' is used deliberately here to demonstrate the underlying intent behind the establishment of these relationships. Despite its business connotations, the use of this term is helpful because it accommodates

\section{Conjuguer les efforts : une collaboration internationale pour assurer une formation post-universitaire virtuelle de qualité sur la gestion de la douleur}

La prise en charge efficace de la douleur est un problème mondial complexe et coûteux qui exige une série de stratégies de formation novatrices visant à permettre des soins de qualité adaptés à la culture. En réaction à ce problème, le Pain Management Research Institute de l'université de Sydney, en Australie, a formé plusieurs alliances stratégiques avec d'autres universités d'outre-mer afin de fournir une formation post-universitaire virtuelle en prise en charge de la douleur. Le présent article explique la raison de conjuguer les efforts et la démarche adoptée pour créer et maintenir ces alliances. Il fournit également un aperçu des avantages, des défis et des possibilités qui s'associent aux initiatives de formation coopérative de cette nature, selon le point de vue de l'établissement, de l'université et de l'étudiant.

a range of different partnership models, those originating from "an arm's-length contract to a joint venture" (5), and draws attention to the importance of having compatible goals when two or more organizations are collaborating to gain a competitive advantage (5-9).

To set the scene, the article briefly reviews the higher education agenda for internationalization, outlining different models and terminology associated with this imperative, and the underpinning drivers influencing universities to join forces. Building on this review, the article provides a case history of the University of Sydney Pain Master's program and the partnership model that has been established. The motivations behind this development, the strategies for maintaining alliances and future directions are subsequently discussed.

\section{INTERNATIONALIZATION, HIGHER EDUCATION AND PAIN MANAGEMENT}

Globalization has firmly placed internationalization on the higher education agenda $(10,11)$. The drivers underpinning this development in Australia, as in many other developed countries, are wide-ranging yet interconnected. From an Australian perspective, they are underscored by economic imperatives. Reductions in government funding to higher education institutions, for instance, have resulted in universities placing a much greater emphasis on strategies that broaden the international student market. Similarly, at the national level, higher education is now viewed as a significant economic export, representing one of the top five trade exports of Australia (12-14).

From an educational perspective, these drivers arise from advances in technology and the need for curriculum innovation. Such developments are influenced by the increasing capabilities of information technology and the opportunities they afford in terms of developing graduates for global citizenship (15). Specifically, in terms of pain management, the advent of online and distance education affords the potential for wider access, exchange and interaction between health professionals at an international level.

Pain Education Unit, Pain Management Research Institute, Royal North Shore Hospital, University of Sydney, Sydney, Australia

Correspondence: A/Prof Philip J Siddall, Pain Management Research Institute, Royal North Shore Hospital, St Leonards,

New South Wales 2065, Australia. e-mail phil.siddall@sydney.edu.au 


\section{TABLE 1}

\section{List of core and elective units}

\begin{tabular}{ll}
\hline Core units & Elective units \\
\hline Introduction to pain & Orofacial pain \\
management & Independent studies in pain \\
Pain mechanisms and & Clinical aspects of neurobiology \\
contributors & Psychology of pain \\
Pain treatment and & Concepts of pain \\
management principles & Musculoskeletal pain \\
Pain conditions & Cancer pain \\
& Pharmacology of pain \\
& Psychological approaches in pain \\
management \\
Disability and pain rehabilitation \\
Pain in children \\
Pain in older people \\
Complementary therapies: \\
Pain management
\end{tabular}

What does 'internationalization' mean?

It is useful to delineate what is meant by 'internationalization' because the terminology describing this activity within the literature is often used interchangeably $(14,16)$. We embrace Knight's definition (17), that internationalization is "the process of integrating an international, intercultural, or global dimension into the purpose, function or delivery of post-secondary education". This definition captures the evolving or developmental quality of the concept, and demonstrates the breadth and depth of this type of activity in purpose, function and delivery. It also acknowledges that there are different forms of internationalization. Essentially, they can be grouped into two broad types: internationalization at home (18) and internationalization abroad (19). The former refers to the strategies adopted within a local curriculum context to provide students with opportunity to develop international and intercultural skills (20). The latter is concerned with strategies that involve the mobility of students and academics (people mobility), programs and course materials (program mobility), or institutions (institution mobility). This aspect of internationalization is now commonly referred to as cross-border education (19).

The international activity described in the present review falls into the category of program mobility because the alliances that have been forged involve the licensing of online course materials to three overseas universities. Effectively, this partnership model involves a franchising arrangement, whereby the local institution delivers the University of Sydney's Pain Management distance education program within a defined geographical region. At this stage, there is no mobility in terms of people or institutions because the partner universities offer whole or part of the Sydney program within a defined area under a contractual arrangement.

\section{CASE HISTORY: THE UNIVERSITY OF SYDNEY EXPERIENCE}

The early years

The postgraduate pain education program was established in 1993, following the appointment of Professor Michael Cousins as head of the Department of Anesthesia and Pain Management, based at Royal North Shore Hospital, University of Sydney. Professor Cousins had a longstanding interest in pain education and, together with a large group of experts from a number of disciplines, developed a postgraduate course based on the core curriculum of the International Association for the Study of Pain (IASP).

In 1996, the course was officially launched through the University of Sydney as an articulated, three-year, part-time Master's award, with a coursework component of two years (Graduate diploma) and a further 12 months for the completion a treatise (20,000 word thesis) project
(Master's). In this first stage of development, while not officially designated as an off-campus course, the program was delivered using a distance delivery framework. Enrolled students undertook independent learning and attended six weekend compulsory residential (on campus) components per year (three per semester). The face-to-face residential component meant that enrollments were limited to a maximum of 30 students per intake. Students were drawn from many disciplines, reflecting the multidisciplinary nature of pain management. The largest numbers were from the disciplines of anesthesiology, nursing, physiotherapy and dentistry. There were several other disciplines represented, albeit in smaller numbers, including clinical psychology, rehabilitation medicine, occupational therapy and palliative care.

In this initial stage, there were several positive and negative aspects to the program. The face-to-face component and small student cohort provided a good environment for student interaction and allowed ready and direct access to professionals and academics in the field. It also engendered good relationships between students who came from different disciplines and settings, but with a common interest in developing their knowledge in pain management. This led to a strong multidisciplinary and collegial atmosphere between students and teaching staff of the program. Notwithstanding these benefits, student enrollment numbers in each cohort were capped, given the available facilities and desire to maintain an interactive classroom environment. Geographical distance also hindered enrollments, with some interstate and international students finding it difficult to attend weekend residential courses several times per year.

\section{Moving to online delivery}

Responding to these challenges, in 1999, a decision was made to offer the course in the online mode, while continuing the face-to-face residential option for those who preferred this delivery approach. Interactive quizzes and tutorials-in-print were developed, and students interacted with one another and expert facilitators through asynchronous discussions using the university's centrally supported learning management system. The dual mode offering was soon disbanded because the face-to-face student demand dropped dramatically following the introduction of the online option. With the introduction of online delivery, the interstate and international enrollments grew substantially, with approximatrly $10 \%$ to $20 \%$ of enrollments coming from overseas, including Europe, North America, South America, Africa and Asia.

\section{Curriculum review}

The move to online delivery, as well as a restructure of postgraduate coursework programs within the university at large, prompted a formal curriculum review in 2004. An outcome of this review was the realignment of the curriculum with the structure and award requirements of other coursework Master's programs at the university. The curriculum was also realigned to embrace a more integrated and flexible approach.

The restructured curriculum was organized into four core (compulsory) units and 12 elective units (Table 1). All students complete the core units, which comprise the graduate certificate. Collectively, these units offer a basic level of information that is considered to be important knowledge for any professional working or with an interest in the field of pain management. This foundation acts as the fundamental knowledge base on which students can then tailor their studies to meet professional needs and aspirations. Students continuing beyond the graduate certificate choose from the electives on offer to complete a graduate diploma (two additional units) or Master's degree (four additional units).

The curriculum review also presented an opportunity to re-evaluate the integration of content across the program. The original curriculum was built around several compulsory units, reflecting the content of the IASP core curriculum. Although comprehensive and modelled using the biopsychosocial framework, these units were delivered along unidisciplinary lines (eg, neurobiology, psychology and pharmacology). In the restructured curriculum, these unidisciplinary areas were 
integrated within the core units to more closely reflect the multidisciplinary, biopsychosocial approach to clinical pain management. This means, for instance, that in one core unit (Pain mechanisms and contributors) students review biological, psychological and environmental contributors, and in another (Pain treatment and management) they explore diagnostic procedures, pharmacology, functional rehabilitation and procedural interventions. Furthermore, during the redevelopment specific attention was placed on the 'constructive alignment' of each unit and the curriculum as a whole (21).

All of these changes were designed to enhance the student learning experience. The application of student learning to clinical situations was encouraged in various ways. Assessment tasks guided students in clinical skills such as development of a diagnostic formulation and treatment plan for a complex pain case. Interactive online discussions and activities, using role-play, debates, and group assignments, were also directed toward the development of clinical reasoning skills and a greater appreciation for the multidisciplinary experience of patient assessment and treatment. Feedback from students highlights that these activities are greatly appreciated, worthwhile and meet their stated objectives. Comments included the following:

This exercise [roundtable discussion activity] highlighted to me the importance of good communication, planning, and teamwork within the multidisciplinary team setting to ensure the best outcome for each patient.

Taking a different role from the actual one we have been doing for some time is not an easy job but a good experience. [T]hrough this experience...we can appreciate the effort and the valuable knowledge of other team members.

These observations highlight that a multidisciplinary program of this nature, and the structured learning activities embedded within it, offers potential for interprofessional education whereby students from different professional backgrounds learn with, from, and about one another to improve collaboration and the quality of care $(22,23)$. The learning activities, for instance, provide students with a structured mechanism for sharing professional knowledge and experience while developing insights into alternative professional viewpoints and approaches, thus broadening understanding and perspectives about the input and roles of different pain practitioners.

On reflection, the move to online delivery, in combination with a restructure of the curriculum, provided many perceived benefits. It provided increased flexibility for students, in terms of access to the program and subject choice, indicated by an increased number of interstate and international enrollments annually. It also meant the costs and time associated with copying and posting reading materials and study guides to students was reduced. Similarly, the demand on lecturers' time (on weekends) reduced, with the online delivery mode opening new opportunities to involve a wider national and even international faculty.

Nevertheless, the move to online delivery was not without challenges. Initially, some students missed the physical classroom environment, despite the strong interactive environment online, while others struggled with computer and internet technology. In addition, reliance on centrally supported technology and services also caused some difficulties, with access to the institution's information technology systems not always being optimal or in line with the needs of off-campus students $(24,25)$. Furthermore, the resources required to develop, prepare, and then update learning materials for online delivery were substantial, which impacted on the program's ability to generate revenue and become self-funding.

A compounding factor was that at an institutional level it is expected that all program costs are met from fee income. Even with healthy annual student enrollments, financial viability is difficult to achieve when institutional 'taxes' are charged against this same fee income. An associated problem is the central determination of program fees, rather than at the program level, for local and international students. The lack of control over the establishment of program costs was an important consideration on several fronts. Not only did this have the potential to hinder local student uptake, but there had been no further growth in the international market, with only very few enrollments from developing countries. It also impacted on the program's capacity to be competitive within an international market, particularly with a growing number of universities (principally in the United Kingdom and the United States) offering similar programs, albeit with slightly different structures and delivery modes.

\section{Internationalizing the Master's program}

To address these concerns, it was decided to develop some strategic alliances with overseas institutions with an interest in pain education. Although this idea had previously been considered and conversations had been conducted with other institutions, administrative and institutional hurdles prevented this development from moving forward in the past.

In 2004, discussions were initiated with two institutions, the University of Edinburgh (UE [United Kingdom]) and the University of California, San Francisco (UCSF [USA]). After some deliberation about the best way to formalize the collaboration, it was agreed to partner with these institutions under separate license agreements commencing in 2005. Consequently, UE and UCSF licensed the materials developed by the University of Sydney and offered them to students in their respective regions (Europe in the case of UE, and North America in the case of UCSF). UE negotiated to offer the full Master's program, whereas UCSF took the graduate certificate level as their starting point, mainly because the university's requirements for establishing a Master's program involved a lengthy approval process. Both of these overseas institutions had their own infrastructure, administration and faculty to host the program, and each institution awarded the degree.

The franchising arrangement that was determined had several advantages for all parties. It allowed a quick and easy start up, with no development costs and little financial risk to the partner institutions. It provided benefits for Sydney University by maximizing the use of materials that had already been developed and increasing the potential reach of the program. It also presented an opportunity to provide local students with greater internationalization of the curriculum, faculty and interaction with overseas students.

While the alliances with UE and UCSF brought many advantages as described above, they failed to address one of the problems previously listed - the lack of uptake of the course in developing countries. Several strategies to tackle this issue were considered. Initially, university management was approached to determine whether a reduction in fees for developing countries could be considered. Similarly, the possibility of scholarships and sponsorships were examined. Unfortunately, neither strategy was considered feasible: internal program fee subsidy was not possible and external funding was limited and difficult to obtain.

The solution was to form another partnership with a university in Manila, The Philippines - The University of Santo Tomas (UST), one of the oldest universities in South East Asia with staff in place committed to pain education. It was decided to form an alliance along similar lines to the other partner programs. The establishment of this alliance was supported by a small internal grant from the University of Sydney and an external grant from the IASP Developing Countries Education Grant Fund. These funds provided assistance with setting up the administrative and technical program requirements and training of prospective faculty. In 2008, the University of Sydney licensed materials to UST, with an agreement that they enrol students from South East Asia, using local administrative support, infrastructure and regional faculty. This agreement effectively enabled the Master's course to be delivered to students in South East Asia at a much lower cost, dramatically increasing the affordability and accessibility of the course for many students in the region.

In summary, the University of Sydney experience helps to illustrate some of the issues involved in the delivery of online postgraduate education in pain management and the issues related to internationalization in education. These experiences and their broader implications are discussed next. 


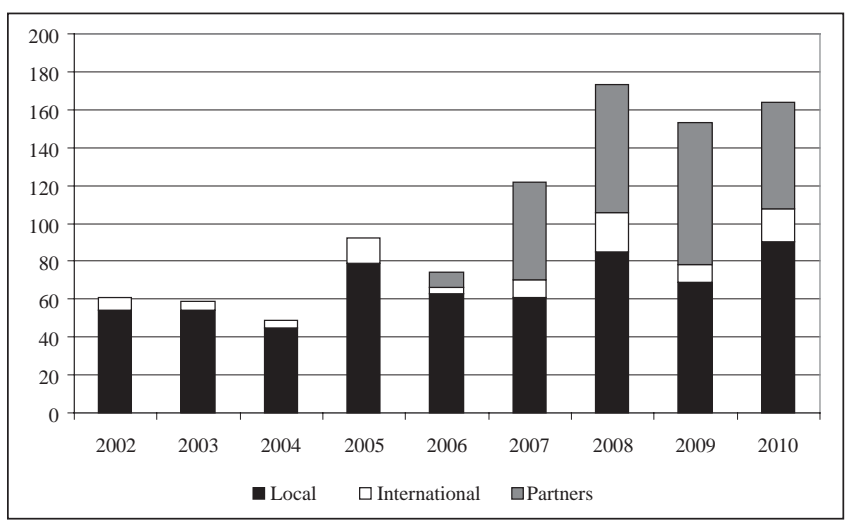

Figure 1) Graph depicting total student enrollments for each year from 2002, including the University of Sydney (Sydney, Australia) enrollments (local and international). The total enrollment figures for all of the international partners from 2006 until 2010 are also included

\section{ESTABLISHING INTERNATIONAL PARTNERSHIPS}

While there were a number of motivations underpinning the establishment of international partnerships between universities, one of the compelling forces driving this development, according to de Wit (11, see also 26) is that of "global competition and collaboration, [because] it is becoming increasingly difficult for individual universities to compete". There are several other forces driving internationalization at home and abroad: these are broadly categorized as political, economic, sociocultural and academic $(9,11,16)$. More specifically, at national and institutional levels, the rationales that have been articulated encompass issues such as human resource development, income generation, nation building, international branding and profile, quality enhancement, and student and staff development (11).

The University of Sydney experience provides some useful insights into strategic alliances, highlighting the interconnected nature of motivations driving such developments. First, it is important to note that each partnership was driven locally, at the program level. Input from the university was mainly at the contractual level. Some of the enablers were the longevity and reputation of the originating program and its faculty and the fully online curriculum, which meant that the learning materials could be easily transferred to another educational context with minimal redevelopment and start-up costs. Another enabler was the professional association between the different stakeholders: the local champions in each partner universities not only had strong reputations as pain experts, but they were also well-known to program staff. These circumstances, as Hüllsmann (27) notes, greatly facilitate the establishment of collaborative ventures.

More specifically, the motivations driving each of these alliances can be categorized into the perceived benefits they would facilitate from an institutional, educational and socioeconomic perspective. At the institutional level, aligning the program with reputable universities overseas would enhance the program standing and its market reach as evidenced by the growth in numbers of students when students from partner programs were included (Figure 1). These alliances provided an opportunity to attract additional revenue, representing another revenue stream at the program and, ultimately, institutional level, thus providing a mechanism for strengthening the viability of the originating program and generating funds for curriculum enhancements. According to Hüllsmann (27), at the program level, such collaborations are often driven by the desire to generate "sufficient surplus (not profit) for quality investments and program sustainability and expansion". The dispersed delivery model (via franchise arrangements) meant that each partner institution was charged with the overall management of local program requirements such as marketing, enrollments and administration, student progression and staffing.

Not surprisingly, from an educational perspective, an associated incentive for building these alliances was to enable continuous
TABLE 2

Overseas partner programs

\begin{tabular}{|c|c|c|c|}
\hline Partner & $\begin{array}{l}\text { Level of } \\
\text { award }\end{array}$ & Region & Duration of agreement \\
\hline$\overline{\mathrm{UE}}$ & Masters & UK and European Union & January 2005 to current \\
\hline UCSF & $\begin{array}{l}\text { Graduate } \\
\text { certificate }\end{array}$ & North America & July 2005 to July $2008 / 9$ \\
\hline UST & Masters & South East Asia (ASEAN) & 2008 to current \\
\hline
\end{tabular}

program improvement and curriculum enhancements in terms of content and student interaction. First, the partner programs offered the potential to gain access to a wider range of expertise in the field of pain management, thus helping to build a broader international perspective into the course content. Second, it afforded economies of scale in terms of teacher development and enhancements to the curriculum. Students would also benefit from the input of a truly international faculty that would better equip them for work in a global world. In other words, the students would be learning from and with international experts and leaders in their field.

From a broader perspective, an important incentive was related to the potential socioeconomic benefits of such alliances: not only in terms of their potential to improve access to high-quality pain education, but also in terms of health care provision for end users, including both patients and their families. Coupled with this was the desire to open up access to the program for developing countries at an affordable cost. Again, it is hoped that this increased access in developing countries will have a flow on effect and help facilitate improved care and management of pain for patients and their families in this region.

\section{MAINTAINING INTERNATIONAL PARTNERSHIPS}

There are a number of philosophical and pragmatic issues, in terms of maintaining international partnerships, to be drawn from this case study. First, however, the current status of each partner program is outlined below (Table 2).

From a philosophical perspective, one of the first considerations is the importance of sharing similar goals and expectations between partner programs. With any collaborative venture, if the different partners have different agendas, difficulties can arise over time. This is evidenced, in some part, by the experience with the UCSF alliance, in which the original license arrangement was not extended beyond its initial three-year term. One of the main reasons for not continuing was that the intention had always been that each partner program would deliver the same level of award. Despite the good working relationship with UCSF, it became increasingly evident that this was not a realistic possibility for UCSF given program approval requirements at a Master's level. A compounding factor was the pending departure of the program champion from the university.

Another broad factor that may impact the maintenance of strategic alliances is the recent developments in the open education resource movement, whereby learning materials are offered freely to users. Although this may be regarded as a positive development for students, it has the potential to create difficulties for programs that are dependent on fee income to provide the resources to develop materials. Students may question why programs charge for materials that are freely available at other sites. Program strategies that focus on and reinforce the crucial role of the learning process, which goes far beyond simple access to materials, will help combat this misconception. The importance of international alliances and the positive role they can have in enhancing the learning experience is another way of addressing this development.

From a pragmatic perspective, with the current partnership model in operation, the responsibility for program governance, delivery, infrastructure needs, copyright issues and quality control resides with each institution context. One of the difficulties arising from this 
situation concerns differences in national regulatory requirements alongside university aspirations and expectations. These difficulties are evidenced in a variety of ways. Financially, each of the partner programs operates with different fee structures in place. Overcoming this issue is difficult because the cost of tuition is determined by government policy (10) and then activated by institutional policy. Clearly, there are ethical and competitive issues at stake here. From a copyright perspective, the allowances for educational institutions differ across different countries. Furthermore, to date, the different university semester timeframes have hindered plans for initiating cross-institutional projects and activities and have impacted timely delivery of minor changes to program content and assessment strategies. In addition to these practical aspects of working together, institutions may have different systems of operation, and quality assurance needs to be in place to ensure that standards are upheld because each partner is, to a certain extent, interdependent.

\section{FUTURE PLANS AND OPPORTUNITIES FOR GROWTH}

To develop and strengthen the type of strategic alliances documented here, the use of online delivery and internationalization of curricula are critical considerations in terms of program growth and sustainability. The approach of single institutions offering individualized curricula, with a reliance on local institutional resources for development and delivery, is appearing increasingly narrow and inefficient. Conversely, the ability to pool resources enables greater capacity to provide other benefits. These include the following: content from the

\section{REFERENCES}

1. Access Economic Pty Limited. The High Price of Pain: The Economic Impact of Persistent Pain in Australia: MBF Foundation in collaboration with University of Sydney Pain Management Research Institute, 2007.

2. Breivik H, Collett B, Ventafridda V, Cohen R, Gallacher D. Survey of chronic pain in Europe: Prevalence, impact on dialy life, and treatment. Eur J Pain 2006;10:287-333.

3. Juniper M, Li TK, Mladsi D. The epidemiology, economic burden, and pharmacological treatment of chronic low back pain in France, Germany, Italy, Spain and the UK: A literature-based review. Expert Opin Pharmacother 2008;10:2581-92.

4. Turk DP, Swanson KP, Tunks ER. Psychological approaches in the treatment of chronic pain patients. When pills, scalpels, and needles are not enough. Can J Psychiatry 2008;53:213.

5. Wahyuni S, Ghauri P, Karsten L. Managing international strategic alliance relationships. Thunderbird International Business Review 2007;49:671-87.

6. Bronder C, Pritzl R. Developing strategic alliances: A conceptual framework for successful co-operation. Eur Manage J 1992;10:412-21.

7. Koza M, Lewin A. Managing partnerships and strategic alliances: Raising the odds of success. Eur Manage J 2000;16:146-51.

8. Saffu K, Mamman A. Mechanics, problems and contribution of tertiary startegic alliances: The case of 22 Australian universities. Int J Educ Manage 1999;13:281-6.

9. Knight J. Internationalisation remodeled: Definition, approaches and rationales. J Studies Int Educ 2004;8:5-31.

10. Altbach PG, Knight J. The internationalisation of higher education: Motivations and realities. J Studies Int Educ 2007;11:290-305.

11. de Wit H. Internationalisation, teaching and learning and strategic partnerships. In: Waugh F, Napier L, eds. Internationalising Learning and Teaching in Academic Settings: Engagement, Collaboration and Sustainability; 23rd November; The University of Sydney: University of Sydney Publishing Service, 2009:12-35.

12. Adams T. The development of international education in Australia: A framework for the future. J Studies Int Educ 2007;11:410-20.

13. Cuthbert D, Smith W, Boey J. What do we really know about the outcomes of Australian international education? A critical review and prospects for future research. J Studies Int Educ 2008;12:255-74. best people at an international level; materials of the highest quality enhanced by shared resources and economy of scale; and student interaction at a global rather than an institutional or even national level.

For these reasons, in terms of the partnership approach described in the present article, the longer-term intention behind the establishment of license agreements has always been to move toward a truly collaborative model, whereby a group of institutions with similar goals, adequate resources and shared commitment, work together to foster excellence in pain management education. In this scenario, each institution would be expected to pool resources, develop materials and deliver the course, working within the unified whole to provide the program to students around the world in a financially, organizationally and educationally seamless manner. However, as the present article highlights, in moving toward this situation, a number of institutional and program level issues need to be resolved.

\section{SUMMARY}

There are a number of challenges in creating and sustaining crossinstitutional and cross-border relationships, where universities partner and work together to deliver high-quality online education in pain management. However, despite these challenges, the ability to overcome them and effectively collaborate can result in advantages and opportunities for each of the partners and their students. The remaining challenge is how to join forces in a much more collaborative manner and overcome some of the barriers identified in the present article, in order to facilitate a truly international curriculum and learning experience for pain practitioners.

14. Harman G. New directions in internationalizing higher education: Australia's development as an exporter of higher education services. Higher Educ Policy 2004;17:101-20.

15. Laurillard D, Stratfold M, Luckin R, Plowman L, Taylor J. Affordances for learning in a non-linear narrative medium. J Interactive Media Educ 2000;2:1-19.

16. Knight J, de Wit H, eds. Quality and Internationalisation in Higher Education. Paris: Organisation for Economic Cooperation and Development, 1999.

17. Knight J. Updated internationalization definition. Int Higher Educ 2003;33:2-3.

18. Nilsson B. Internationalisation at home - theory and praxis. European Association for International Education Forum 12, December 1999, Maastricht, The Netherlands.

19. Knight J. GATS, Trade and Higher Education: Perspective $2003-$ Where are we? London: The Observatory on Borderless Higher Education, 2003.

20. Organization for Economic Co-operation and Development. Internationalisation and Trade in Higher Education: Opportunities and Challenges. Paris: OECD Publishing, 2004.

21. Biggs J, Tang C. Teaching for Quality Learning at University, 3rd edn. Maidenhead, Berkshire: The Society for Research in Higher Eduction and Open University Press, 2007.

22. Barr H, Koppel I, Reeves S, Hammick M, Freeth D. Effective Interprofessional Education: Arguement, Assumption and Evidence. Oxford: Blackwell, 2005.

23. Devonshire E, Wozniak H. Working together: Developing e-Learning activities to promote interprofessional learning. Synergy 2006; 23:25-8.

24. Cluett L, Skene J. Improving postgraduate coursework student experience: Barriers and the role of the institution. Australian Universities Quality Forum; July 5 to 7, 2006; Perth, Western Australia, 2006.

25. Guri-Rosenblit S. Distance education and "e-learning": Not the same thing. Higher Educ 2005;49:467-93.

26. Kehm B, Teichler U. Research on internationalisation in higher education. J Studies Int Educ 2007;11:260-73.

27. Hüllsmann T. A cost-analysis of Oldenburg University's two Graduate Certificate Programs offered as part of the Online Masters of Distance Eduction (OMDE). In: Bernath U, Rubin E, eds. Reflections on Teaching and learning in an online Master Program: A case study. Oldenburg: Bibliotheks und Informationssystem der Universitat Oldenburg, 2003:167-226. 


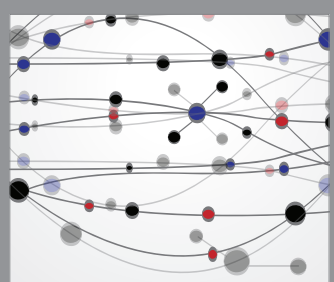

The Scientific World Journal
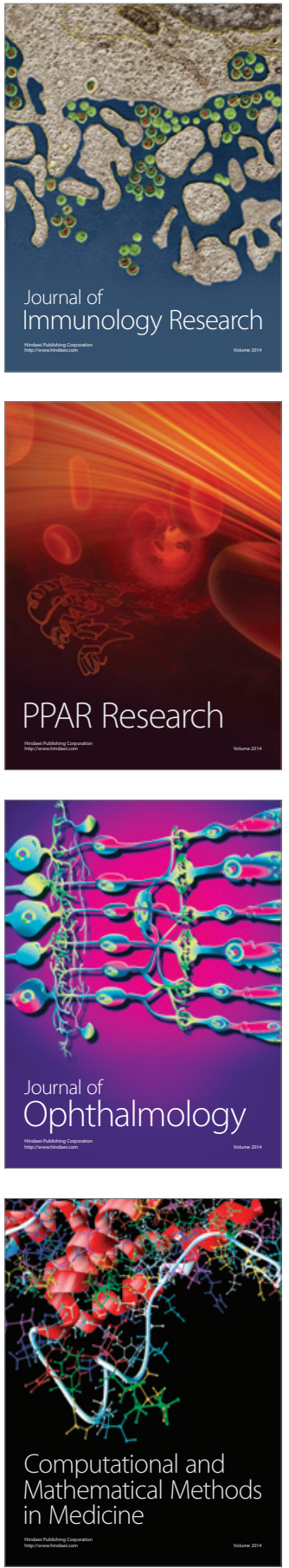

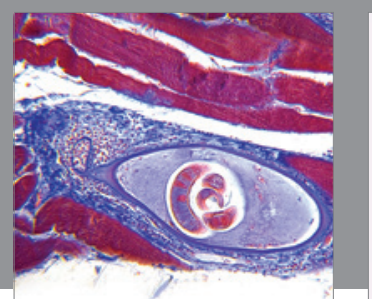

Gastroenterology Research and Practice

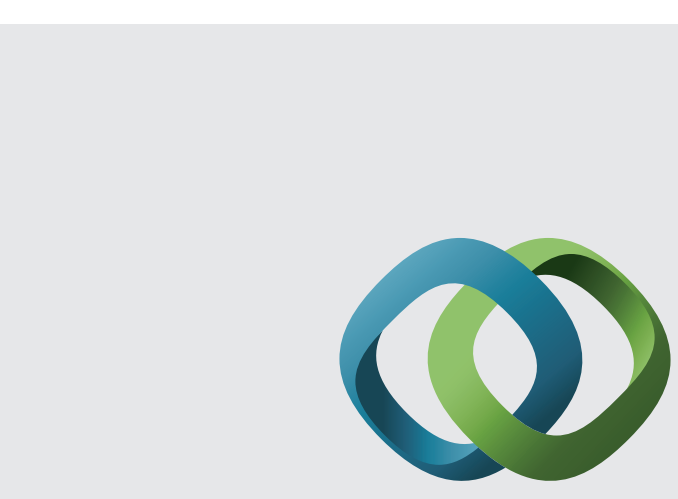

\section{Hindawi}

Submit your manuscripts at

http://www.hindawi.com
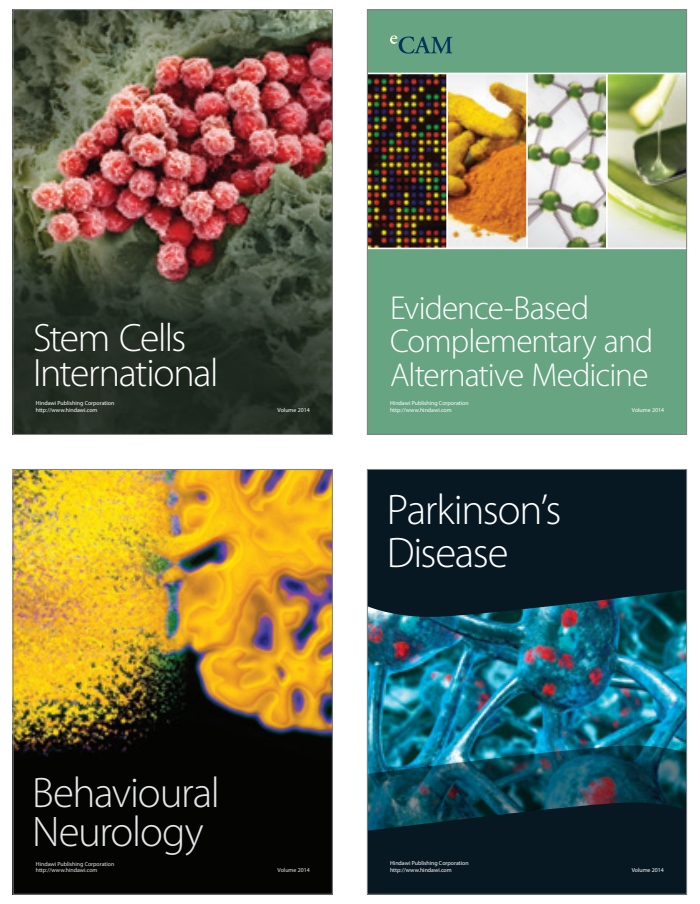
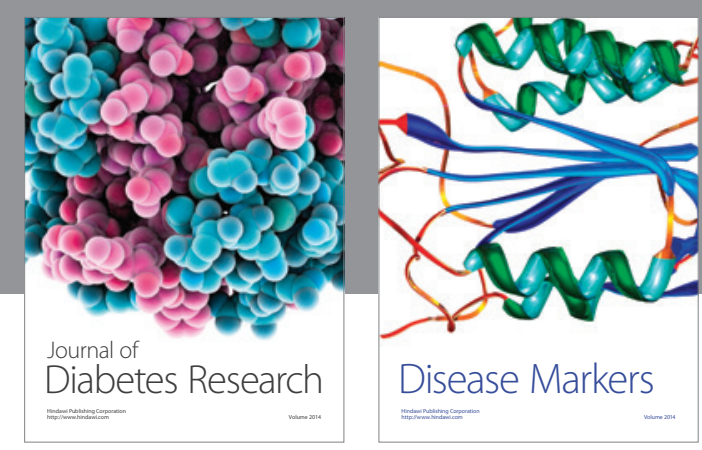

Disease Markers
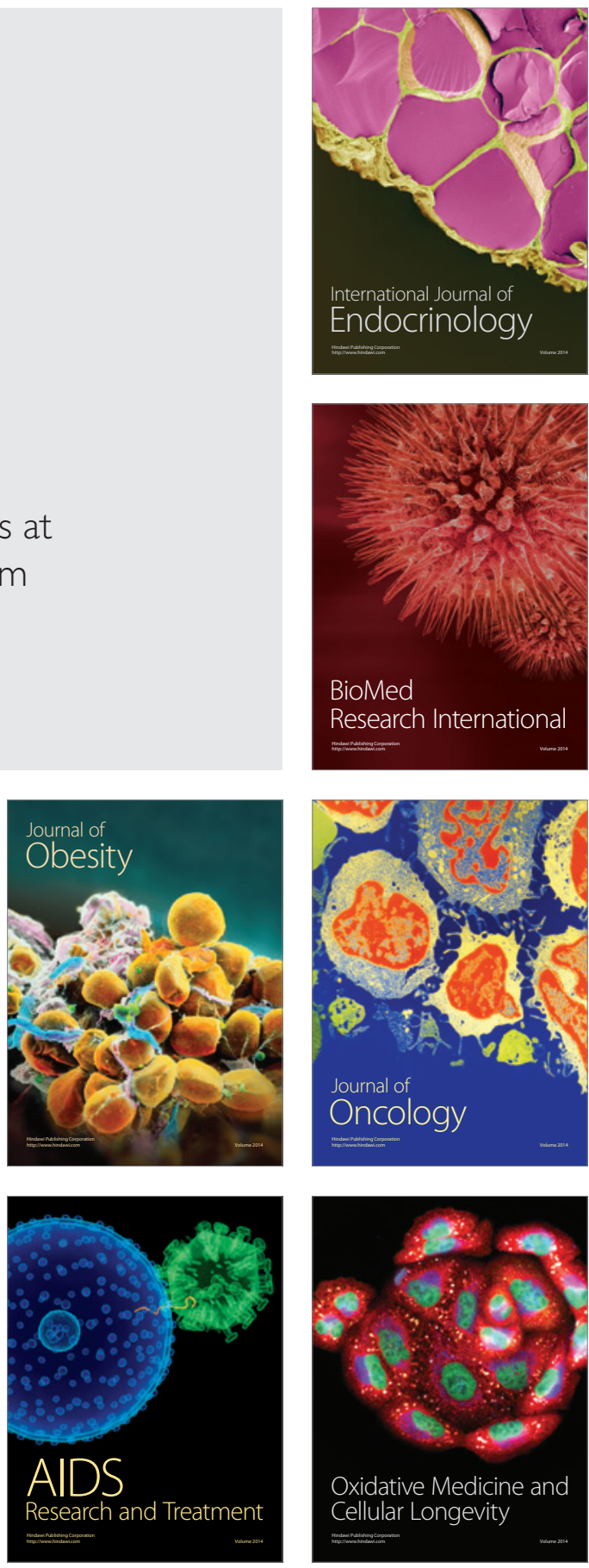